\title{
Diálogos contemporâneos da produçáo de autoria feminina
}

\author{
Tanay Gonçalves Notargiacomo*
}

Universidade Federal de Santa Catarina

Resumo: Entrevista realizada em fevereiro de 2013 com a escritora Elvira Vigna, em que se debatem questóes a respeito da literatura de autoria feminina bem como a produção no século XXI, tendo em vista seus procedimentos que perpassam um processo de ditadura militar.

Palavras-chave: Produçóes de autoria feminina. Literatura contemporânea. Internet.

Tanay Gonçalves Notargiacomo: Como se deu o seu relacionamento com a literatura e, em seguida, com o ato de escrita?

Elvira Vigna: A leitura literária: na infância e em bibliotecas, principalmente. A escrita literária: já como jovem adulta, e por acaso. Sem emprego como jornalista (época da ditadura), montei uma editora.

Tanay: Como foi o processo de publicaçáo de seu primeiro livro: desde sua opçáo de ser escritora até chegar a uma editora?

* Mestre em Literatura, Universidade Federal de Santa Catarina, trabalha e tem interesse na área de Literatura e Mulher e Literatura Contemporânea.

Esta obra está licenciada sob uma Licença Creative Commons. 
Elvira: Não foi separado. Eu era a dona da editora Bonde. E não foi propriamente uma 'opçâo'. Náo achei que me 'tornava escritora' naquele momento. Apenas que editava um livro. O fiz estimulada pela Fernanda Lopes de Almeida, de quem eu lançava o primeiro livro. E por Maria Alice Barroso, que estava à frente do Instituto Nacional do Livro, do MEC. Ou seja, tive a ajuda de duas mulheres. Depois, outras duas me ajudaram e muito. Duas editoras: Maria Antonieta Cunha, da antiga Miguilim - na época em que me dediquei à literatura infantil; e mais recentemente, já com a literatura para adultos, Maria Emilia Bender, com quem tratei de meus livros na Companhia das Letras.

Tanay: Como uma escritora mulher, produtora de literatura de autoria feminina, você já enfrentou alguma dificuldade na questão de gênero diante das leitoras ou leitores, editoras, academia, críticas ou críticos?

Elvira: No Recife, onde fui por conta de uma palestra, enquanto esperávamos (eu e outros escritores, todos homens) formaram-se duas mesas. Uma, dos 'verdadeiros escritores' que falavam alto, riam e onde estavam os organizadores. A outra mesa era de mulheres, na sua maioria poetas locais que eu não conhecia e para onde me encaminharam. Acho que esse episódio, engraçado, foi uma ocasião em que ficou clara a questão de gênero em um ambiente literário. Mais recente, em Porto Alegre, um colega de mesa falou longamente sobre a etimologia do verbo foder. Não estava no tema previsto. Eu era a única mulher da mesa e, antes, para terminar minha fala sobre livros clássicos, tinha lido um pequeno trecho de um romance meu em que havia referência aos clássicos - e também a uma trepada. Achei que podia ser uma resposta a minha "ousadia" de, como mulher, falar (ou escrever) sobre sexo. Há outros episódios, mas são mais engraçados do que graves. Os graves não aparecem. Se dão na exclusão tácita, muda, de listas de presença, antologias locais. Para voltar ao Recife, naquela mesma ocasião me presentearam com uma antologia de contos que havia sido recém-publicada. Sem sequer uma mulher no seu índice. 
Tanay: Qual seu posicionamento em relação aos estudos de gênero, à militância na/da área, fatos esses que estáo cada vez mais em voga?

Elvira: Leio, quando me mandam, as monografias que citam meus livros. Mas não tenho uma atuação direta ou militante.

Tanay: Além da sua opiniáo, você já participou de debates, grupos de discussão ou mesmo lutas e manifestações a respeito do tema?

Elvira: Não.

Tanay: Como escritora do século XXI, que diferenças você encontra nas produçóes anteriores a respeito dos temas?

Elvira: Produçóes ficcionais? Acho que a presença da autoria feminina aumentou. Em parte, provavelmente, por causa dos estudos acadêmicos sobre a questão do gênero. As produçôes acadêmicas eu não acompanho, não saberia dizer.

Tanay: Ainda em comparação ao século XXI, quais eram e quais são os procedimentos de escrita que, para você, apresentam diferenças?

Elvira: Olha, meus textos teóricos detalham isso sem parar. Os procedimentos sáo radicalmente diferentes dos do modernismo do século XX. Costumo me apoiar muito na análise das artes plásticas porque nelas os procedimentos da contemporaneidade estão atuando de forma mais forte do que na literatura. Esses textos teóricos (palestras, artigos e críticas) estâo no meu site (ver http://vigna.com.br/) para quem quiser consultar.

Tanay: Em seus romances notamos um fio condutor que perpassa as relaçôes humanas. Qual o mote temático de suas produçôes?

Elvira: Eu noto que me repito no sentido de que sempre conto uma história em que uma história é contada. Não é bem uma metalinguagem. É apenas uma exposição do processo de como uma história é criada, suas hesitações, falhas. A exposição de processos, aliás, é um dos procedimentos presentes na atuação estética contemporânea, tema da pergunta anterior. Outro desses procedimentos bem característicos do contemporâneo, e que também está presente nos meus romances, é uma ausência de fim determinístico para a ação e os personagens. Há 
uma abertura para o leitor "formar" a história. Ou uma possibilidade de história. E aí está uma relação humana, de mim com o leitor, meu sócio.

Tanay: Como se deu sua participação na ditadura brasileira? Você considera que isso refletiu em seu modo de escrita? E nos enredos? Percebemos que no livro Nada a Dizer a ditadura surge como reflexo psicológico e relacional nas personagens.

Elvira: Não participei de açôes diretas contra a ditadura. Eu trabalhava muito, pois tinha uma filha que dependia de mim. E também porque grande parte dessa luta nascia no ambiente burguês das universidades. E não frequentei universidade. Comecei a trabalhar antes mesmo de terminar o ensino médio. As pessoas no meu entorno, contudo, eram jornalistas, artistas e militantes. Muitos deles foram presos, incluindo meu atual companheiro, com quem estou desde 1972 - ano que marcou o auge da ditadura militar, no governo Médici. Acho que viver na ditadura foi uma experiência muito marcante para nós, que fomos as vítimas. Além da ameaça constante de prisão ou simples sumiço, havia a questão da sobrevivência material. Para algumas profissóes ou atividades - como jornalismo, editar livro ou desenhar, que era o que eu sabia fazer - arranjar trabalho era difícil.

Tanay: Alguma reivindicação, como escritora?

Elvira: Escritores como eu - longe das listas de mais vendidos não reivindicam. Se esforçam por existir.

Tanay: O que pensa do advento da internet como propagador de escritas?

Elvira: Sou grande fã da internet.

Tanay: Você notou alguma recorrência de área de atuação específica em seu público leitor? O que acha do acontecimento de seus livros estarem presentes nas aulas de literatura das universidades, sendo lido pelas e pelos estudantes de Letras, pesquisadoras e pesquisadores? Você imaginava esse alcance?

Elvira: Não sei se posso dizer que meus livros estão presentes nas aulas de literatura, assim, em uma generalização. Mas fico muitíssimo contente que estejam em algumas aulas. Gosto da conversa com esse 258 
público leitor. Tenho um enorme prazer quando me escrevem, analisam ou opinam sobre o que fiz.

\section{Elvira Vigna por Elvira Vigna}

$\mathrm{Na}$ carteira de trabalho sou jornalista. Trabalhei por diversos períodos em O Globo, para a Folha de São Paulo na época em que morei no exterior, para O Estado de São Paulo de 1999 a 2003. O último foi o Jornal do Brasil, onde publiquei artigos sobre arte contemporânea até o fim de 2006. Em 2007 passei a publicar os artigos no site Aguarrás (ISSN: 1980-7767), até fechar. Agora publico pelo Études Lusophones da Sorbonne IV (em português). Fui também editora. Minha editora, a Bonde, durou cinco anos, a revista marginal-literária $A$ Pomba, que mantive com Eduardo Prado, um pouco menos. Em 1988 abri uma empresa de traduçóes, a Earte, que funciona até hoje. Tenho um diploma de literatura francesa de 1975, emitido pela Universidade de Nancy (França), em convênio com a Aliança Francesa. Com este diploma aceito como equivalente a uma graduação em Letras - fiz um mestrado na Faculdade de Comunicação da Universidade Federal do Rio de Janeiro em 1979, na área de Teoria da Significação. Em 1984 e 1985, fiz cursos de extensão universitária na Parsons School of Design de Nova York, dando seguimento assim à minha segunda área profissional, a da imagem. Antes, eu já havia feito o curso de três anos com especialização em gravura no Instituto de Belas Artes do Rio de Janeiro. O Instituto de Belas Artes é a escola que virou Escola de Artes Visuais do Parque Lage. Em 2008, já morando em São Paulo, fiz o curso de um ano do Masp sobre história da arte. Fiz duas exposiçóes individuais onde apresentei técnicas experimentais. A primeira, Pinturas cafajestes, na biblioteca da Cultura Inglesa do Rio de Janeiro em 1990, mostrou a tinta automotiva industrial como possibilidade técnica. A segunda, em 1998 na Vila Riso $(\mathrm{RJ})$, trouxe a impressão em grandes dimensóes sobreposta à mesma tinta industrial. Esta se chamou Imagens mentirosas e teve a apresentação de Gerd Borhneim. Fiz uma terceira exposição, junto com Caró. Foi a Dimensóes do tempo, em 1996, onde explorávamos as diferenças de 
visão e técnica entre mãe e filha na abordagem de um mesmo tema, o tempo. Esta exposição foi no Planetário da Gávea. Fui também, por quatro anos, capista exclusiva de uma revista cultural japonesa editada pela Ed. Kodansha. Em 2003, entrei em uma escola de cinema, a Darcy Ribeiro (RJ) onde completei o curso de roteiro. Como exercício roteirizei livros meus. Já havia sido co-roteirista há muito tempo, ajudando o Edu no Balada dos infiéis, de Geraldo Santos Pereira. Meus primeiros livros foram dirigidos a crianças e jovens. Depois, parei de escrever livros, ficando só com jornalismo. Quando voltei aos livros, escrevia para adultos e não mais para crianças. Sete anos e um dia, meu primeiro romance, é de 1988 e fala sobre um grupo de amigos durante os sete anos da abertura política brasileira. Fora de catálogo, ele está aqui no site, texto integral. Nasci no Rio de janeiro em $1947 .{ }^{2}$

[Entrevista recebida em março de 2013 para compor a corrente edição especial]

\section{Dialogues of contemporary productions of female authorship}

Abstract: Interview conducted in February 2013 with writer Elvira Vigna, which discuss questions about the literature of female authorship and production in the twenty-first century, in view of its procedures that go through a process of military dictatorship.

Keywords: Productions of female authorship. Contemporary literature. Internet.

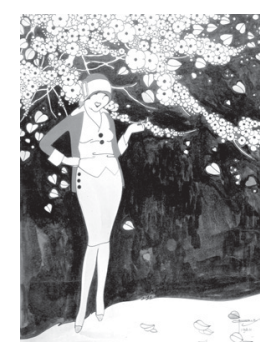

\footnotetext{
${ }^{2}$ Biografia disponível no endereço eletrônico da escritora. Disponível em: <http://vigna. com.br/biografia/>. 